Macedonian Pharmaceutical Bulletin, 66 (Suppl 1) 185 - 186 (2020)

Online ISSN $1857-8969$

UDC: $615.24 .074: 543.544 .5 .068 .7$

DOI: 10.33320/maced.pharm.bull.2020.66.03.092

Short communication

\title{
A fast and simple HPLC method for determination of mesalazine impurities $A$ and $C$ in raw material and finished pharmaceutical products
}

\author{
Marjan Piponski*, Tanja Bakovska Stoimenova, Irena Slaveska Spirevska, Stefan Stefov, \\ Elena Lazarevska Todevska, Marina Topkoska, Gordana Trendovska Serafimovska
}

Replek Farm Ltd., Kozle 188, 1000 Skopje, N. Macedonia

\section{Introduction}

Mesalazine, also known as mesalamine or 5-aminosalicylic acid (5-ASA), is a medication used in the management of inflammatory bowel disease, including ulcerative colitis and Crohn's disease. It is generally used for treatment of mild to moderately severe conditions, especially for maintenance of remission (Iacucci et al., 2010).

According to the monograph of mesalazine in the current edition of the European pharmacopoeia (Ph. Eur), this active substance has thirteen specified impurities and a few other detectable impurities, which can be determined by three analytical procedures using different chromatographic conditions. The monograph of mesalazine in Ph. Eur (as well as in the British pharmacopoeia-BP) prescribes one HPLC method for determination of impurities $\mathrm{A}$ and $\mathrm{C}$, another HPLC method for determination of impurity $\mathrm{K}$, and a third HPLC method for analysis of the parameter related substances (determination of the other ten specified impurities, as well as unspecified impurities). The test for determination of impurities A (4aminophenol) and C (2-aminophenol) prescribes gradient elution HPLC method, with a run time of 29 minutes, using acid mobile phase composed of $1.0 \mathrm{~g} / \mathrm{L}$ phosphoric acid $R$ and $2.2 \mathrm{~g} / \mathrm{L}$ perchloric acid $R$ in water, and $1 \mathrm{~g} / \mathrm{L}$ phosphoric acid $R$ and 1.7 $\mathrm{g} / \mathrm{L}$ perchloric acid $R$ in acetonitrile, with flow rate $1.0 \mathrm{~mL} / \mathrm{min}$, use of acidic $\mathrm{pH}$ resistant end-capped Nucleodur C18 HPLC column $250 \mathrm{~mm} \times 4.6 \mathrm{~mm}, 3$ $\mu \mathrm{m}$, working at backpressure of about 300 bars, achieving separation potency of more than 15000 NTP (number of theoretical plates) from the available theoretically calculated 42000 NTP. The mesalazine monograph of in the United States pharmacopoeia (USP) prescribes gas chromatography (GC) method for determination of these two impurities.

The aim of this study was development of a fast and simple, isocratic chromatographic method for determination of mesalazine impurities $\mathrm{A}$ and $\mathrm{C}$.

\section{Materials and methods}

The following reagents were used: methanol, 85\% o-phosphoric acid and 70-72\% perchloric acid, purchased from Merck, Darmstdat, Germany; potassium hexafluorophosphate $\left(\mathrm{KPF}_{6}\right), \geq 99 \%$ purchased from Sigma-Aldrich, USA; while the deionized water was "in house" product prepared with conductivity of $0.05 \mu \mathrm{S} / \mathrm{cm}$.

The following instruments were used: analytical balance Mettler Toledo AG285, pH-metter Metrohm $827 \mathrm{pH} \mathrm{Lab}$ and IKA orbital shaker KS 260 basic.

\footnotetext{
*piponski99@gmail.com
} 
The RC (regenerated cellulose) $0.45 \mu \mathrm{m}$ syringe filters were purchased from Agilent Technologies (USA).

Two HPLC systems were used: Dionex Ultimate 3000 UHPLC system controlled by Chromeleon software, version 6.80, composed of quaternary LPG pump, autosampler, column compartment and four channel UV-Vis detector; and Shimadzu Nexera XR UPLC system with LPG quaternary pump with degasser, autosempler, PDA detector, column oven and controller, controlled by Lab Solutions software, version 5.97.The HPLC column, Discovery C18 150 $\mathrm{mm} \times 4.6 \mathrm{~mm}, 5 \mu \mathrm{m}$, was purchased from SigmaAldrich, USA.

The active substance mesalasine was obtained from Replek Farm Ltd., and the impurities, mesalazine impurity A CRS and mesalazine impurity C CRS were purchased from EDQM. All sample and standard solutions were prepared in accordance with the method for testing of impurities $\mathrm{A}$ and $\mathrm{C}$ from $\mathrm{Ph}$. Eur. monograph for mesalazine active substance.

\section{Results and discussion}

We developed a fast and simple isocratic chromatographic method using a different concept of mobile phase composition, based on the recognized chaotropic characteristics of potassium hexafluorophosphate $\left(\mathrm{KPF}_{6}\right)$ dissolved in acidic medium, enabling increased column retention of molecules containing nitrogen atom in their structure (Kazakevich \& Lobrutto, 2007).

The mobile phase consisted of $2 \% \quad v / v$ acetonitrile and $98 \% v / v$ buffer composed $0.05 \% v / v$ o-phosporic acid with added $0.3 \% w / v \mathrm{KPF}_{6}$.

The developed method uses HPLC column Discovery C18 $150 \mathrm{~mm} \times 4.6 \mathrm{~mm}, 5 \mu \mathrm{m}$, UV detection at $220 \mathrm{~nm}$, mobile phase flow rate of $1.0 \mathrm{~mL} / \mathrm{min}$ and column oven temperature set at 35 ${ }^{\circ} \mathrm{C}$. These chromatographic conditions generated different appearance of the chromatogram regarding the retention times of mesalazine and its impurities $\mathrm{A}$ and C.Using the method prescribed in the Ph. Eur. monograph, elution order of the substances of interest is the following: impurity A with RRT $\sim 0.5$, impurity $\mathrm{C}$ with RRT $\sim 0.9$ and mesalazine. Using the new developed method, the obtained elution order is different: impurity A with RRT $\sim 0.8$, mesalazine with RT $\sim 3.4$ minutes and impurity C with RRT 1.4. The separation between all substances of interest was satisfactory and complete.

Analysis of mesalazine active substance was performed using the method from the $\mathrm{Ph}$. Eur. monograph for mesalazine and the new developed method. The obtained results for impurities $\mathrm{A}$ and $\mathrm{C}$ of mesalazine were comparable for both methods, with relative difference of each result for every specified impurity lower than $2 \%$.

\section{Conclusion}

The advantages of the newly developed isocratic HPLC method for determination of mesalazine impurity $\mathrm{A}$ and $\mathrm{C}$ are the following :

- The use of isocratic elution enables shorter run time of about 6 minutes, versus the gradient elution described in $\mathrm{Ph}$. Eur. and BP monographs for mesalazine, requiring longer run time of about 29 minutes;

- The use of shorter RP C18 column with $5 \mu \mathrm{m}$ particles resulted in separation power of about 10000 NTP (available theoretically calculated is 15000 NTP), instead of longer, special acid-resistant C18 column with $3 \mu \mathrm{m}$ particles, enabling shorter time for column equilibration and analysis;

- Lower working backpressure using the new developed method, up to 85 bars, versus $~ 300$ bars using the HPLC column and chromatographic conditions prescribed in the Pharmacopoeia.

\section{References}

British Pharmacopoeia, 2018. British Pharmacopoeia Commission - The Stationery Office: London.

European Pharmacopoeia, $9^{\text {th }}$ ed., 2016-2017. European Directorate for the Quality of Medicines \& Healthcare - Council of Europe: Strasbourg.

Iacucci, M., De Silva, S., Ghosh, S., 2010. Mesalazine in inflammatory Bowel Disease: A trendy topic once again?. Can. J. Gastroenterol. 24, 127-133.

LoBrutto, R., Kazakevich, Y., 2007. Reversed-Phase HPLC: Chaotropic Effect, in: Kazakevich, Y., LoBrutto, R. (Eds.), HPLC for Pharmaceutical Scientists. John Wiley \& Sons, New Jersey, USA, pp. 206-227.

The United States Pharmacopeia / The National Formulary (USP 40-NF 35), 2017. The United States Pharmacopeia Convention: Rockville.

Maced. Pharm. Bull. 66 (Suppl 1) 185 - 186 (2020) 